\title{
Phenotypic plasticity and the colonization of new habitats: a study of a colonial spider in the Chaco region and the Cerrado
}

\author{
F. Fernández Campón ${ }^{1,2,3} \cdot$ V. Nisaka Solferini ${ }^{4} \cdot$ R. Carrara $^{1,2} \cdot$ A. E. Marvaldi ${ }^{5,6}$. \\ V. Confalonieri ${ }^{7,8}$
}

Received: 29 July 2020 / Accepted: 13 January 2021 / Published online: 7 February 2021

(c) The Author(s), under exclusive licence to Springer Nature Switzerland AG part of Springer Nature 2021

\begin{abstract}
In social animals, group prey capture could facilitate colonization of new areas with low resource availability. Parawixia bistriata is a colonial spider inhabiting seasonal dry forests and mesic habitats in South America. Individuals capture prey as a group, which allows individuals to broaden their foraging niche by incorporating large prey that cannot be subdued in solitary captures. P. bistriata exhibits two behavioural ecotypes a "dry" (plastic) ecotype which modifies individual's tendency to capture prey in a group depending on food resources and a "wet" (fixed) ecotype, whose tendency to group prey capture is only modulated by the size of the prey but not by prey availability. By reconstructing the range expansion of the species using phylogeographic and species distribution modelling techniques, we indirectly examined whether group prey capture could have helped P. bistriata in colonization of low resource habitats. Based on cytochrome $c$ oxidase subunit I gene genealogy, we found older populations in northern Cerrado in Brazil with more recent populations located further south in Dry and Humid Chaco in Argentina, with the latter being the most derived. Species distribution modelling for each ecotype suggests that suitable habitat for each ecotype started to overlap at some point during the Last Glacial Maximum (21 ky BP). These results suggest that $P$. bistriata expanded from northern Cerrado south to the Gran Chaco, being able to colonize mesic habitats at a later stage when individuals reached southern territories in the Chaco. This evidence is opposite to the idea that GPC facilitated $P$. bistriata colonization from mesic to harsher environments. However, plasticity in group prey capture could have been important to allow individuals to establish in mesic habitats by reducing the cost of group capture when under high resource levels.
\end{abstract}

Keywords Parawixia bistriata $\cdot$ Phylogeography $\cdot$ Species distribution model $\cdot$ Chaco region $\cdot$ Cerrado

F. Fernández Campón

fcampon@mendoza-conicet.gob.ar

Extended author information available on the last page of the article 


\section{Introduction}

There are certain behavioural traits that can facilitate colonization of a new environment by a species (Sol et al. 2002; Duckworth and Badyaev 2007). Given that the success of a colonizer depends on its ability to survive and reproduce under the new ecological conditions, individuals should be preadapted to the new environment or be flexible enough to quickly respond in an adaptive manner to the new environmental conditions (e.g., behavioural flexibility, Wright et al. 2010; Webb et al. 2014; Beever et al. 2017).

In group living species, there could be specific traits that facilitate moving and establishing into a new habitat (Spinks et al. 2000; Lövy et al. 2012; Cornwallis et al. 2017). In these species, it is assumed that evolution of sociality was favoured under the environmental conditions of the habitat where the species originated. However, when social species inhabit multiple habitats with different environmental conditions (e.g., resource), it is interesting to know if specific traits could have helped in the colonization of new environments when the source and the new habitats differ in resource availability.

Spiders are a particularly interesting group to develop studies on social behaviour because it mainly comprises solitary and aggressive species. In social species, group behaviours can be important in terms of colonizing ability (Spinks et al. 2000; Lövy et al. 2012; Cornwallis et al. 2017). As opposed to social insects which can be considered reproductive societies (i.e., group characteristics are mainly driven by the reproductive function) social species of spiders are considered foraging societies (Whitehouse and Lubin 2005), although other benefits in reproductive and survival aspects are gained by grouping (Avilés and Guevara 2017; Grinsted et al. 2019). Thus, foraging related traits could potentially help in the colonization of habitats in social spiders.

It is generally assumed that high prey availability levels and large prey size are necessary for groups to occur (Powers and Avilés, 2007; Yip, et al. 2008; Avilés and Guevara 2017; Grinsted et al. 2020) and that spider groups behave as "foraging flocks" that obtain the benefits of a large capture when they group their capture webs (Rypstra 1989). This can explain why most social species of spiders are found in tropical humid areas where insect prey is very abundant (Riechert 1985; Majer et al. 2015). However, there are social spiders inhabiting habitats with different resource levels. In these cases, we could ask whether social related traits could have facilitated the colonization of the new environments.

In some social species of spiders found under low prey availability conditions such as semi-arid habitats, groups of individuals remain in a colony benefiting by an increase in prey availability as they can exploit microhabitats such as open spaces which serve as flying corridors for insect prey (Lubin 1974). In addition, by grouping their webs spiders also profit from an increase in prey capture (ricochet effect; Rypstra 1989; Uetz 1979; Rao 2009). Adding to the benefits of group living, group prey capture (GPC) is another trait expressed by some spider species. Through GPC individuals can capture prey of large size that cannot be subdued by a solitary individual (Avilés and Guevara 2017 and references therein). This results in an increase in the amplitude of their foraging niche and decreases the variability in food intake compared to solitary species (Grinsted et al. 2019; Majer et al. 2018) allowing individuals to obtain more food despite the low prey levels found in those environments.

Parawixia bistriata (Rengger 1836) is a colonial orb weaving spider (Araneidae) from South America. It mainly inhabits semi-arid habitats such as the Cerrado in Brazil and the Dry Chaco within the Gran Chaco in Argentina and Paraguay. In addition, it is also found in mesic habitats such as the Humid Chaco. These habitats differ in 
prey availability levels and the species shows behavioural flexibility in the expression of GPC depending on resource levels. Individuals capture prey in a group when prey is larger than the spider (Fowler and Gobbi 1988; Fernández Campón 2007). GPC occurs when a prey landing in a resident's web attracts neighbours due to the vibrations produced. The larger the prey, the further the vibration travels and the more spiders are attracted to the resident's web. First, the resident spider signals the neighbours not to enter its web by shaking it with its legs. When group capture occurs, this signal is ignored, and the resident and the first neighbours that arrive at the web participate in the capture of the prey. Once the prey is subdued, other individuals join and feed communally. The number of individuals engaging in prey capture and feeding depends on the size of the prey and the habitat type (capture: 2-9 individuals; feeding: 2-22 individuals). Interactions during GPC can sometimes be aggressive (probably modulated by prey levels) (Fernández Campón 2007). In P. bistriata, there are different behavioural ecotypes. A "wet" ecotype typical of mesic environments which shows a fixed tendency to GPC that does not depend on local prey availability conditions but only on prey size, and a "dry" (flexible) ecotype which under low prey availability conditions shows a higher tendency towards GPC compared to high prey availability conditions (Fernández Campón 2008). Studies carried out on this species suggest that GPC is important for their survival in dry habitats, with low prey availability. The absence of flexibility dependent on prey abundance of the wet ecotype impairs their growth and survival as seen when individuals were translocated to dry habitats under low prey conditions (Fernández Campón 2005, 2008). Under these circumstances, wet ecotype individuals show a lower growth rate and fecundity (estimated on the number of eggs per sac) than individuals that can adjust their tendency to capture prey as a group (“dry” ecotype) (Fernández Campón 2010). Interactions with conspecifics during GPC can sometimes be aggressive, implying costs to individuals participating in GPC (Grinsted and Lubin 2019). Thus, plasticity in this behaviour may be an advantage in habitats with low and more variable prey availability, whereas lack of plasticity in GPC expression is not detrimental in habitats with high and more stable prey levels.

It is possible to gain insight into a possible role of GPC in the colonization of new habitats by the use of phylogeographic studies and paleoclimatic information to determine the trajectory of colonization of the species over evolutionary time. In this study we use this approach to indirectly examine possible pathways in which GPC could have contributed to the colonization history of P. bistriata. We examine two possible scenarios. One in which this species originated and evolved in habitats with high prey conditions and the expression of GPC favoured the colonization of habitats with harsher conditions; and the other, in which P. bistriata originated in low prey condition environments with the flexible expression of GPC and later colonized high prey habitats with a later loss of behavioural flexibility in GPC that might have been favoured by the high prey levels and higher costs of aggressive interactions during GPC or by stochastic events (Lubin 1974; Fernández Campón 2007; Yip et al. 2017; Quero et al. 2020). Following the "high prey level" hypothesis we would expect oldest populations of $P$. bistriata occurring in mesic habitats and more derived ones in semi-arid environments. Alternatively, under the second scenario, we would expect the populations from mesic habitats to be more derived than those from arid environments. 


\section{Materials and methods}

\section{Sample collection, DNA extraction, amplification and sequencing}

We collected adults of $P$. bistriata in most of the species' range, comprising 64 individuals (one per colony) from 16 locations in the Gran Chaco in Argentina and Paraguay and the Brazilian Cerrado (Table 1; Fig. 1). Opisthosomas and palps were stored in absolute ethanol for species confirmation and deposited in the Arachnology Collection of IADIZA (CAI) (Mendoza, Argentina). Genomic DNA was extracted from one or two legs using an adapted "salting out" protocol (Sunnucks and Hales 1996). We amplified the mitochondrial region of the cytochrome $c$ oxidase subunit I (COI) with the primers C1-J-1718 y C1-N2776 (Framenau et al. 2010). The PCR conditions followed were: a denaturation step of $3^{\prime}$ at $95{ }^{\circ} \mathrm{C}, 30$ cycles of $94{ }^{\circ} \mathrm{C}$ for $1 ', 50{ }^{\circ} \mathrm{C}$ for $1^{\prime}$ and $72{ }^{\circ} \mathrm{C}$ for $2^{\prime}$, and a final extension step at $72{ }^{\circ} \mathrm{C}$ for $2^{\prime}$. PCR reactions consisted of $1 \mu \mathrm{L}$ of DNA, $0.2 \mu \mathrm{L}$ of $5 \mathrm{U}$ Taq DNA Polymerase (Genbiotech), 2-2.8 $\mu \mathrm{L}$ of $25 \mathrm{mM} \mathrm{MgCl} 2$ (Genbiotech), $2.5 \mu \mathrm{L}$ of $10 \times \mathrm{KCl}$ Buffer (Genbiotech), $0.5-1 \mu \mathrm{L}$ of $10 \mathrm{mM}$ dNTP mix (GE Healthcare), $0.5 \mu \mathrm{L}$ of each primer $10 \mu \mathrm{M}$, and ultrapure $\mathrm{H} 2 \mathrm{O}$ until completing a volume of $25 \mu \mathrm{L}$. The PCR products were purified and bi-directionally sequenced with the Sanger method, by means of the Sequencing Service of "Unidad de Genómica de INTA-Castelar" (Buenos Aires, Argentina).

\section{Alignment, genetic diversity and haplotype reconstruction}

The sequences were aligned in Geneious ${ }^{\circledR}$ 9.1.8 and were visually inspected; we found the best fitting substitution model according to the AIC on jMODELTEST 2.0 (Darriba et al. 2012). Diversity indices were calculated on Arlequin 3.5 (Excoffier and Lischer 2010).

Table 1 List with sample locations of Parawixia bistriata's populations, with details of type of biome and geospatial coordinates. Code for populations names is between brackets

\begin{tabular}{llll}
\hline Localion & Biome & Latitude & Longitude \\
\hline Brasil-Brasilia (Bra) & Cerrado & -15.945 & -47.938 \\
Brasil_Estrela do Sul (ES) & Cerrado & -18.745 & -47.692 \\
Brasil-Nerópolis (Ne) & Cerrado & -16.406 & -49.223 \\
Brasil-Santo Antonio da Platina (SA) & Cerrado & -23.481 & -50.110 \\
Brasil-Bonito (Bo) & Cerrado & -21.161 & -56.463 \\
Paraguay-R9 km 40 Pozo Colorado (40 k) & Dry Chaco & -23.493 & -58.381 \\
Paraguay-R9 km 427 (427 k) & Dry Chaco & -22.557 & -59.875 \\
Paraguay-PaiPukú (Pai) & Dry Chaco & -24.335 & -58.195 \\
Argentina-Ceres (Cer) & Dry Chaco & -29.890 & -61.939 \\
Argentina-Parque Nacional Copo (Copo) & Dry Chaco & -26.009 & -61.834 \\
Argentina-Frías (Fri) & Dry Chaco & -28.650 & -65.151 \\
Argentina-Laguna Yema (LY) & Dry Chaco & -24.303 & -61.282 \\
Argentina-Ruta Nacional 34 (R34) & Dry Chaco & -23.979 & -64.799 \\
Argentina-Mburucuyá (MB) & Humid Chaco & -28.006 & -58.006 \\
Argentina-Río Guayquiraro (RG) & Humid Chaco & -30.412 & -59.579 \\
Argentina-Sagastume (Suma) & Humid Chaco & -33.684 & -58.843 \\
\hline
\end{tabular}


Relationships among haplotypes were visualized on median-joining networks (Bandelt et al. 1999) built on POPART (http://popart.otago.ac.nz).

\section{Population structure}

We estimated the genetic distances among populations in Arlequin 3.5 (Excoffier and Lischer 2010). To verify the presence of isolation-by-distance among our samples, we analysed the correlation between the populations' genetic and geographic distances through Mantel tests. We assessed the population structure between biomes Cerrado and Chaco with $\mathrm{F}_{\mathrm{ST}}$ values calculated on Arlequin 3.5. We also performed an analysis of molecular variance (AMOVA) using (1) Cerrado and Chaco (dry and humid combined), and (2) Cerrado, Dry Chaco and Humid Chaco as separate groups, to test the structure both between and within these biomes. Population structure was also assessed on BAPS 6.0 (Corander et al. 2008), which determines the most likely number of clusters (k) within a given group of sequences. We allowed $\mathrm{k}$ to vary between 1 and 20 .

\section{Phylogenetic inferences and divergence times}

We conducted a one locus *Beast analysis (Heled and Drummond 2010) in BEAST 1.8.0 to estimate the divergence among major mitochondrial lineages (as determined by BAPS) taking into account incomplete lineage sorting. We used a strict clock with a substitution rate of $0.0112(\mathrm{SD}=0.001)$ substitutions/site/million years. Bidegaray-Batista and Arnedo (2011) estimated this rate for the Dysderidae family based on the well-resolved geochronology of the Mediterranean basin. Recently, Kuntner et al. (2013) found that the substitution rates estimated for the orbicularian families (which include Araneidae) overlapped with those from the Dysderidae, allowing these rates to be implemented to estimate the divergence times for orbicularian taxa. Two runs were conducted with 150 million generations, sampling every 15,000 generations. The resulting trees and log files from each of the two runs were combined using the computer program LogCombiner v1.6.1 (http:// beast.bio.ed.ac.uk/LogCombiner). Convergence with a stationary distribution was checked on Tracer 1.5 (Rambaut et al. 2014) through values of Effective Sample Sizes $>200$ for each prior. The posterior probability density of the combined tree and log files was summarized as a maximum clade credibility tree using TreeAnnotator v1.6.1 (http://beast.bio. ed.ac.uk/ TreeAnnotator) (Rambaut et al. 2014). The mean and 95\% highest posterior density estimates of divergence times and the posterior probabilities of inferred clades were visualized using the computer program FigTree v1.3.1 (http://beast.bio.ed.ac.uk/FigTree) (Rambaut 2012). In addition, the tree obtained was projected onto the grid of geographical coordinates using Phylowood (Landis and Bedford 2014) to visualize the phylogeographic reconstruction in space.

\section{Paleoclimatic models}

We employed Species Distribution Modelling (SDM) to reconstruct the spatial distribution of $P$. bistriata's dry and wet ecotypes in the past. SDM is a statistical tool that uses the association between different environmental variables and known locations of species presence to define the abiotic conditions within which populations can be maintained, assuming actual conditions were similar in the past (niche conservationism) (Guisan and 
Fig. 1 Maps with Parawixia bistriata's sampling locations in Argentina, Brazil and Paraguay. Cerrado biome is shown in dark grey, Dry Chaco in intermediate grey and Humid Chaco in light grey. Size of the pie charts is proportional to the number of individuals sampled in a locality (largest: five individuals, smallest: two individuals). a Pie charts for each population represent the proportion of mitochondrial haplotypes. Similar colour indicates same haplotype. b Locations coloured according to the four haplotype groups obtained with BAPS, location codes as in Table 1

Thuillier 2005). Because behavioural ecotypes are associated with different habitats (environmental conditions) and we wanted to use SDM as an independent approach for testing directional expansion of $P$. bistriata between habitat types, we modelled the distribution of each ecotype separately, based on the actual occurrence of populations in dry (Cerrado and Dry Chaco) and wet (Humid Chaco) habitats. We used the presence data collected in field trips, Levi (1992), museum holding databases (Museo Argentino de Ciencias NaturalesMACN and Museo Nacional de Historia Natural de Paraguay-MNHNP), and checked presence data from the web databases iNaturalist (www.inaturalist.org) and Sistema Nacional de Datos Biológicos (SNDB; https://datos.sndb.mincyt.gob.ar) by F. Fernández Campón. To avoid spatial autocorrelation in the output of the model we only used those records that were 1.5 degrees $(150 \mathrm{~km})$ from each other. This was a prerequisite for the model to be robust and reliable when projected to past times. That left us with 19 data points for the dry and six occurrence points for the wet ecotype.

As a first step, we used actual environmental information and species spatial occurrences to fit a model that explain the potential spatial distribution of $P$. bistriata ecotypes in the present. As second step, the model previously fitted was re-projected to past by using environmental information of Last Glacial Maximum (LGM) and Last Interglacial period (LIG) to reconstruct species potential distribution for those periods of time. The environmental information considered was only climatic because climate has a strong influence on invertebrate physiology and distribution ranges (Brandt et al. 2020; Kellermann et al. 2012; Addo-Bediako et al. 2000) and there exist available climatic data on actual and past conditions. Climate layers at a resolution of 2.5 arc-min were obtained from the WorldClim 1.4 free climate database http://www.worldclim.org/), which comprises values for 19 bioclimatic (bc) variables, averaging the 1950-2000 period (Hijmans et al. 2005). Prior to the modelling process, we performed Pearson's correlation analysis on variables in order to avoid spatial correlation (Pearson $>0.90$ ) and reduce over-parametrization. As a result, eight bioclimatic predictors were used: (bc2) mean monthly temperature range; (bc4) temperature seasonality; (bc5) maximum temperature of warmest month; (bc9) mean temperature of driest quarter; (bc13) precipitation of wettest month; (bc14) precipitation of driest month; (bc15) precipitation seasonality; (bc18) precipitation of warmest quarter. Paleoclimate layers representing the LGM (21 ky BP) and LIG (130 ky BP) were those used to reproject to past the species spatial distribution. Paleoclimatic layers were downloaded from the WorldClim website (http://www.worldclim.org/), which include downscaled climate data from different Global Climate Models (GCMs), based on original data made available by CMIP5 (Coupled Model Intercomparison Project Phase 5; http://cmip-pcmdi.llnl. gov/cmip5/); data were calibrated using WorldClim 1.4 as baseline'current' climate. For the LGM we used two models: the CCSM4, Community Climate System Model (CCSM), National Center for Atmospheric Research; and the MIROC-ESM, Model for Interdisciplinary Research on Climate (MIROC), Japan Agency for Marine-Earth Science and Technology, Atmosphere and Ocean Research Institute, The University of Tokyo, and National Institute for Environmental Studies. For LIG, we obtained past climatic data from WorldClim too, based on Otto-Bliesner et al. (2006). 




(B)

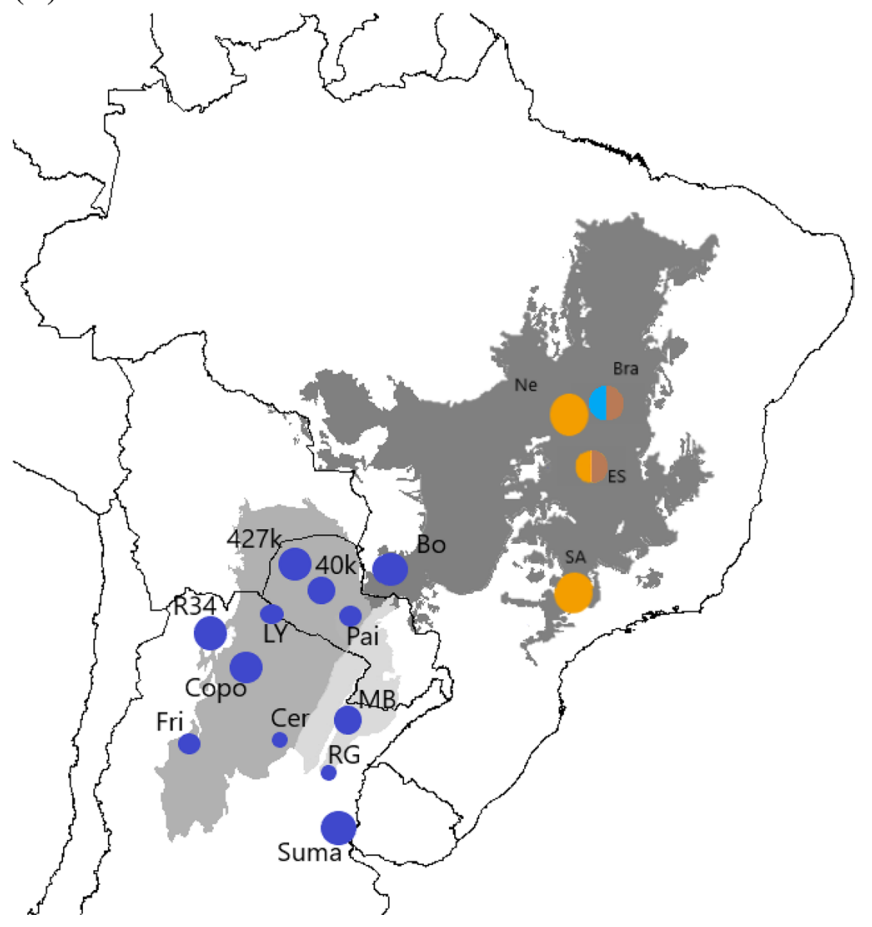


Models were built using the maximum-entropy algorithm MaxEnt version 3.3.3k of the software (http://www.cs. princeton.edu/ schapire/maxent). We selected MaxEnt because it works well with relatively small sample sizes (Hernandez et al. 2006, 2008; Wisz et al. 2008; Tognelli et al. 2009). As MaxEnt selects variable features and protects against overfitting internally through regularization (Quinn et al. 2018), we identified optimal levels of model complexity in the model using the R package ENMeval (Muscarella et al. 2014). ENMeval performs automated runs and evaluations of ecological niche models by selecting among different combination of scores of regularization and features to obtain models that maximize predictive ability and avoid overfitting (Muscarella et al. 2014). Specifically, we used a range of values for the regularization multiplier $(\beta)(0.5-4$ in increments of 0.5$)$, and considered linear, quadratic, hinge, product threshold and categorical feature classes. Feature classes are functions created by MaxEnt for each environmental variable (Phillips and Dudík 2008) and the regularization multiplier controls the smoothness of the distribution curve. As occurrence data on P. bistriata were relatively low, we ran modelling with leave-one-out data partition as recommended by Pearson et al. (2007) and used 10.000 random background points. Finally, we selected the best fitting model to that with the lowest AIC value.

\section{Results}

\section{Genetic diversity}

TN93 + G was the best fitting model for nucleotide substitution (Tamura and Nei 1993). The dataset presented 29 haplotypes (Table A.1). Most haplotypes were restricted to one locality, except some which were shared among locations within Chaco (Fig. 1a). Diversity levels were very low (Table 2). Six out of 16 populations were monomorphic, two in Cerrado and four in Chaco (Table A.1).

\section{Genetic structure}

Haplotypes were structured into four groups according to BAPS (Fig. 1b; Table A.2): three groups within the Cerrado and one group comprising all Chaco locations plus a locality in the Cerrado that borders the Pantanal (Bo). BAPS groups correspond to clades defined in the phylogenetic tree, with ancestral clades including Cerrado populations (Fig. 2, see below). The haplotype network (Fig. 3) can be divided into the four groups inferred by BAPs. In the network, group four (Chaco+Bonito) shows a star-like topology, with an haplotype (H_19) from LY and R34 locations in Dry Chaco occupying a central position, and many low frequency haplotypes emerging from it (i.e. younger ones). Haplotypes from MB, RG and Suma locations in the Humid Chaco occupy derived positions within the star, indicating their younger age relative to haplotypes from Dry Chaco. Fst value between biomes showed important structuring (Table 2). AMOVA analyses using biomes Cerrado and Chaco as geographical groups supported the spatial structure detected by BAPs and the Fst: while a third of the variability is explained by differences between biomes indicating strong structure at that level, similar percentages of variability were shown among population within biomes and within populations (Table $3 \mathrm{a}$ ). In addition, when considering Dry and Humid Chaco as well as the Cerrado (Table 3b), the AMOVA showed that variability among populations within biomes was important (39.85\%), however, a significant 
Table 2 Genetic diversity indices for $P$. bistriata's populations and biomes (Bonito is grouped with Chaco populations according to group 4 in BAPS). $\mathrm{N}=$ number of sequences; $h=$ number of haplotypes; ss = number of segregating sites; $\mathrm{Hd}=$ haplotype diversity; $\pi=$ nucleotide diversity; Fst = fixation index, $\mathrm{sd}=$ standard deviation

\begin{tabular}{lrrrlll}
\hline Population & N & h & ss & Hd (sd) & II (sd) & Fst \\
\hline Bra & 4 & 2 & 31 & $1.0000(0.176)$ & $0.025(0.017)$ & \\
ES & 4 & 2 & 38 & $0.667(0.204)$ & $0.036(0.024)$ & \\
Ne & 5 & 1 & 0 & $0.000(0.000)$ & $0.000(0.000)$ & \\
SA & 5 & 1 & 0 & $0.000(0.000)$ & $0.000(0.000)$ & \\
Bo & 5 & 2 & 18 & $0.900(0.161)$ & $0.011(0.007)$ & \\
$40 \mathrm{k}$ & 4 & 2 & 12 & $0.500(0.265)$ & $0.008(0.006)$ & \\
$427 \mathrm{k}$ & 5 & 2 & 10 & $0.800(0.164)$ & $0.008(0.005)$ & \\
Pai & 3 & 2 & 5 & $1.000(0.272)$ & $0.004(0.004)$ & \\
Cer & 2 & 1 & 0 & $0.000(0.000)$ & $0.000(0.000)$ & \\
Copo & 5 & 2 & 3 & $0.600(0.175)$ & $0.002(0.002)$ & \\
Fri & 3 & 2 & 3 & $0.667(0.314)$ & $0.003(0.002)$ & \\
LY & 3 & 2 & 9 & $0.667(0.314)$ & $0.008(0.007)$ & \\
R34 & 5 & 2 & 15 & $0.700(0.218)$ & $0.012(0.007)$ & \\
MB & 4 & 1 & 0 & $0.000(0.000)$ & $0.000(0.000)$ & \\
RG & 2 & 1 & 0 & $0.000(0.000)$ & $0.000(0.000)$ & \\
Suma & 5 & 1 & 0 & $0.000(0.000)$ & $0.000(0.000)$ & \\
Cerrado & 18 & 8 & 56 & $0.856(0.003)$ & $0.024(0.012)$ & 0.317 \\
Chaco + Bonito & 46 & 25 & 51 & $0.963(0.000)$ & $0.012(0.006)$ & \\
\hline & & & & & &
\end{tabular}

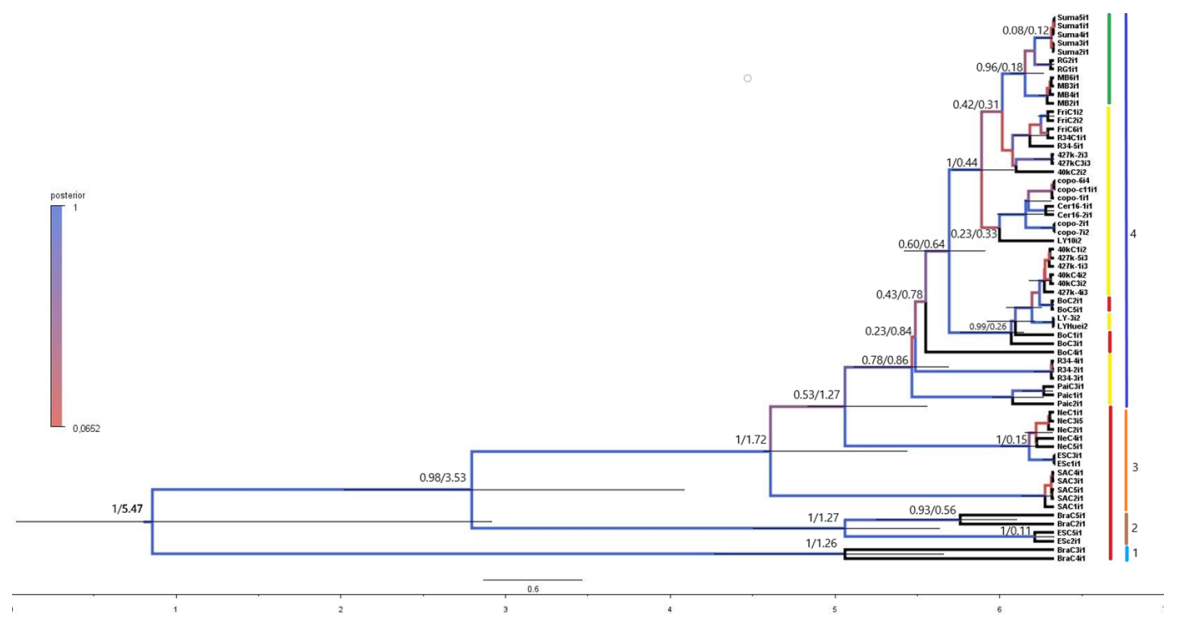

Fig. 2 Bayesian gene tree inferred for P. bistriata using COI dataset. Colours of branches indicate posterior probabilities according to the reference shown at the left of the tree. Node age is shown at each node with the horizontal bar indicating 95\% HPD. First coloured lines at the right of the populations sampled show the biome in which they were found. Red: Cerrado; yellow: Dry Chaco; green: Humid Chaco. Second coloured line and numbers show individuals within each BAPS group, colour of groups as in Fig. 1. Numbers at the nodes indicate both posterior probability/node age

percentage of variability was found among the three biomes (28.25\%). The Mantel tests did not indicate significant correlation between genetic and geographical distances $(r=0.095$, $p=0.241$ from 1000 randomizations) implying an absence of isolation by distance. 


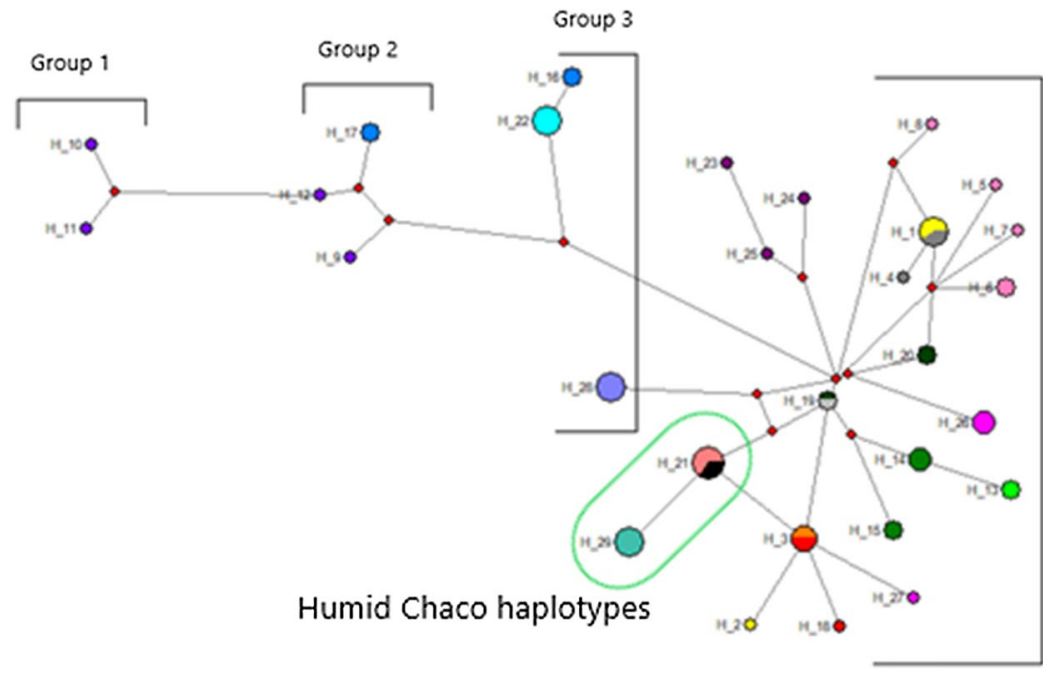

Group 4

Fig. 3 Haplotype network showing the 29 haplotypes, divided into the four groups inferred by BAPS: Group 1-3 occur in the Cerrado and Group 4 in Chaco. Haplotypes found in the Humid Chaco are circled. Haplotypes corresponding to the different individuals are shown in Table A.1. Circle size is proportional to frequency, colours correspond to populations and red dots represent missing intermediate haplotypes

Table 3 Results of the analysis of molecular variance (AMOVA) for mitochondrial datasets for P. bistriata considering biomes: A) Cerrado and Chaco (Dry and Humid combined); and B) Cerrado, Dry Chaco and Humid Chaco as groups; d.f. = degrees of freedom

\begin{tabular}{lclr}
\hline Source of variation & d.f & Variation (\%) & P-value \\
\hline A) Cerrado and Chaco & & & \\
$\quad$ Among biomes & 1 & 32.94 & $p=0.001$ \\
Among populations within biomes & 14 & 38.13 & $p<0.001$ \\
Within populations & 48 & 28.94 & $p<0.001$ \\
B) Cerrado, Dry Chaco and Humid Chaco & & & $p<0.001$ \\
Among biomes & 2 & 28.25 & $p<0.001$ \\
Among populations within biomes & 13 & 39.85 & $p<0.001$ \\
Within populations & 48 & 31.91 &
\end{tabular}

\section{Phylogenetic inferences and divergence times}

The gene tree obtained from the *Beast analysis (Fig. 2) recovered groups similar to those inferred by BAPS (Table A.2): groups 1 and 2 from Cerrado both resolve as monophyletic, with highest posterior probabilities; group 3 -the most southern group from Cerradoresolves as paraphyletic, including group 4 from Chaco as a derived and monophyletic lineage. Haplotypes from group 1, located at northern Cerrado can be considered the most ancient, branching off first from the last common ancestor at approximately 5,47 million years before present (My BP) (95\% highest posterior density, HPD 6.30-3.41). Conversely, haplotypes belonging to the Humid Chaco emerges as the most derived cluster within 
group 4, supported by a high posterior probability. The clade including all haplotypes from Chaco populations and Bonito last shared a common ancestor with a clade from Cerrado that would have existed at about 1.27 My BP (95\% HPD 1.5-0.77). This could be considered the time of divergence between spiders from both biomes, Chaco and Cerrado. Unlike clades located in Cerrado, some clades within Chaco (which in BAPS form one same cluster) show weaker support values, one exception is the lineage from the Humid Chaco. According to this analysis this latter clade is relatively young, with a time of divergence estimated in $31 \mathrm{ky} \mathrm{BP}$ (95\% HPD 26-3). An animation of the inferred geographic distribution changes of $P$. bistriata through time can be viewed in http://mlandis.github.io/phylo wood/ by opening the txt matrix in Supplementary Materials.

\section{Paleoclimatic models (species distribution model)}

The best fitted model was lqhpt 1.5 and had an AIC $=727.87$ with a delta AIC of 2.48 compared to the second-best model. It included seven parameters, excluding (bc5) maximum temperature of warmest month from the overall set of environmental variables considered. The model for the LIG (130 ky BP) scenario shows disjointed suitable areas for the dry ecotype occurrence (Fig. 4a). They are in north-western Argentina and Paraguay and eastern Brazil. There are also smaller areas in the north west of the continent in Venezuela and north-eastern Brazil. During the LGM (21 ky BP), results from both MIROC and CCSM models mostly agree (CCSM simulation is shown Supplementary Material A.4). They show an expansion of suitable habitat with the previous disjointed areas now in contact and forming a large area covering much of the Cerrado, the Chaco and further to the north west (Fig. 4b). At present times, the location of suitable habitat is similar to that of the LIG but more expanded (Fig. 4c).

Suitable areas for occurrence of the wet ecotype during LIG are in the Amazon region and north-western Cerrado and do not overlap with those areas of the dry ecotype, especially in Brazil (Fig. 4a). There is another smaller area in Venezuela showing some overlap with suitable areas of occurrence of the dry ecotype and another area with low probability of occurrence ( $<0.5$ in south east of Brazil and Paraguay). During the LGM the two models show an important reduction of suitable areas for the wet ecotype restricted to what it is now part of the Humid Chaco (in north-eastern Argentina and Paraguay) with some overlap with the dry ecotype in very reduced parts. There is also another small area in northern Brazil in what it is the Atlantic Forest today (Fig. 4b). The current scenario shows one area located in the Humid Chaco similar to that in the LIG model but with a larger extension. Suitable areas for the occurrence of dry and wet ecotypes show more overlap at present times (Fig. 4C).

\section{Discussion}

Using indirect approaches by reconstructing the range expansion of $P$. bistriata and the paleo and current distribution of ecological niches of dry and wet ecotypes, we provided information that serves to indirectly examine the relevance of expression of GPC on colonization of new habitats. We evaluated two contrasting hypotheses. One hypothesis was based on the premise that high prey levels are necessary to allow grouping of individuals (by increasing tolerance among conspecifics). Under these conditions GPC occurred, and colonization of harsher environments was facilitated through GPC as $P$. bistriata 



(B) DRY
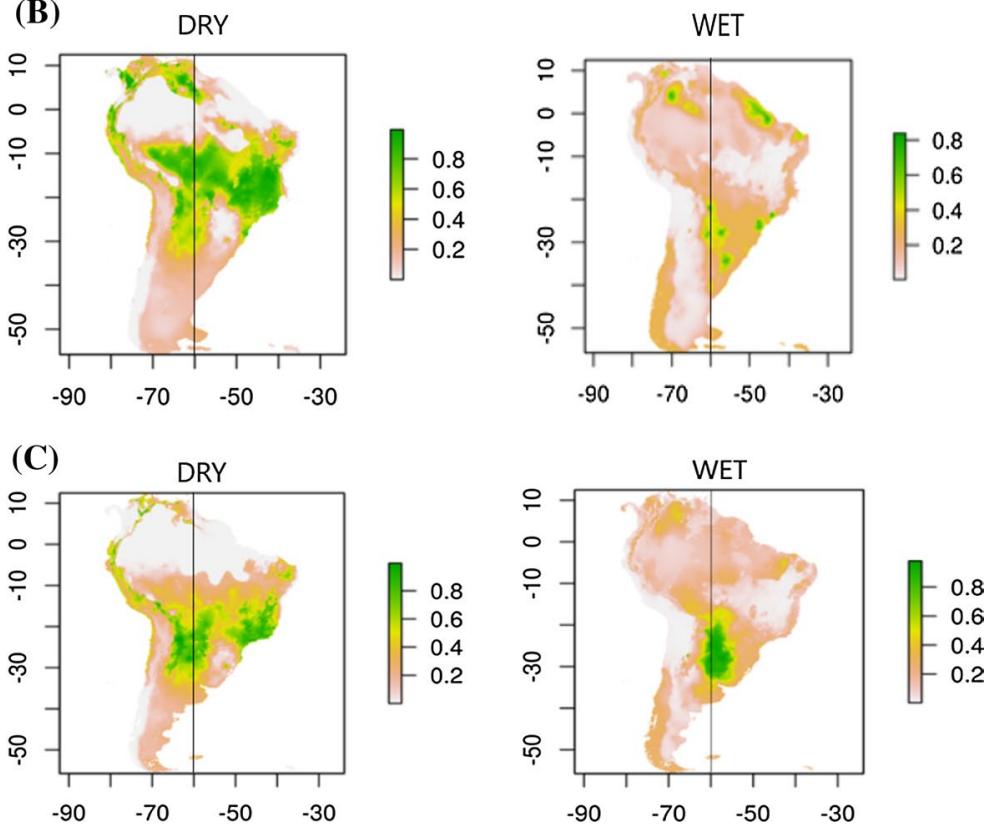

Fig. 4 Models of geographic distribution of "dry" (left) and "wet" (right) ecotypes of P. bistriata obtained in MaxEnt at different geological times. a LIG: Last Interglacial period (130 ky BP), b LG: Last Glacial Maximum (21 ky BP) and present. Results from LG are shown based on the MIROC climatic model. CCSM model simulations are shown in Fig A.4 in the Supplementary material (see text for explanation). Scales at the right of each map indicate the probability of occurrence of the species in a specific area

can broaden their foraging niche and survive despite lower prey conditions thanks to the expression of this behaviour.

Contrary to what is expected following the "high prey level" hypothesis, commonly suggested for the evolution of sociality in spiders, we found that P. bistriata's oldest populations are located in north central Brazil within a "dry" biome (Fig. 2). They later expanded to the Dry Chaco finally colonizing the Humid Chaco. Furthermore, distribution models for both ecotypes support this finding. When modelling environmentally suitable areas for the occurrence of the dry and wet ecotypes, we found that environmental conditions for both ecotypes start to show some overlap during the Last Glacial Maximum 
(LGM) at approximately $21 \mathrm{ky}$ BP. At some point between the Last Interglacial period (LIG; 129-116 ky BP) and the LGM, environmental conditions for both ecotypes started to overlap making it possible for the dry ecotype to colonize wet biomes (Fig 4). Divergence times estimated in the COI genealogy show that the clade containing populations of the Humid Chaco diverged from one of the branches corresponding to Dry Chaco populations around $310 \mathrm{ky} \mathrm{BP}$ and started to diverge within the Humid Chaco approximately 180 ky ago. These data are not in agreement with the hypothesis that sociality and GPC in $P$. bistriata originated in mesic habitats and colonization of harsher environments such as the Dry Chaco was facilitated by the expression of group prey capture and feeding.

What is supported by the molecular data is the hypothesis that $P$. bistriata originated in dry environments and colonization of mesic habitats (Humid Chaco) occurred in the last stages of their range expansion. Divergence times based solely on gene genealogies usually overestimate populations divergence times (Edwards and Beerli 2000; McCormack et al. 2011) and these estimates based on $P$. bistriata's COI genealogy have large confidence intervals. Taking this into account and despite estimates are not identical, data inferred using both approaches give support to the idea that $P$. bistriata originated in dry biomes with colonization of wet biomes occurring later in the expansion of the range of the species. We can infer that $P$. bistriata's ancestor was found in northern South America and ancestral populations of this species expanded from the northern Cerrado towards the south until entering the Chaco region. This suggests that behavioural flexibility or plasticity in GPC is an ancestral trait and this plasticity was later lost when the species colonized and established in mesic habitats with higher levels and less variability in prey abundance. Plasticity in a trait that is relevant for a species survival is expected to be favoured under variable conditions such as the Cerrado and Dry Chaco, both with marked dry and wet seasons. P. bistriata is the only social species so far described within the genus. This is a Neotropical genus with most species found in the Amazone area, with some species present in central America and up to the humid tropical regions of southern Mexico (Levi 1992). In semi-arid and seasonal habitats such as the Cerrado and the Chaco there are patches of open areas that serve as corridors for flying insects. $P$. bistriata is found in these microenvironments and at the border of forest patches not within the forest canopy. It seems clear that one of the advantages of grouping in this species is the possibility of exploiting this "prey-rich" microenvironments unavailable for solitary species. In addition, although GPC may have enabled $P$. bistriata to expand its foraging niche and reduce variability in food intake, individuals in the colony still seem to suffer from low prey level as seen by the variability in body condition which is stronger than in wet habitats populations (Fernández Campón 2005).

Shrinking and expansion of suitable habitat during glacial periods, such as expansion of the rain forests towards Cerrado and Chaco (Sobral-Souza et al. 2015; Bartoleti et al. 2017; Trujillo-Arias et al. 2017) may have contributed to the structuring observed in the mitochondrial dataset and may have selected for individuals expressing plasticity in GPC. The results agree with the "plasticity first" hypothesis (Levis and Pfennig 2016) which postulates that while ancestral populations are expected to be plastic, these plastic responses might become genetically accommodated or assimilated in derived populations (Stein and Bell 2019). That is, there is a change in the extent of plasticity due to a shift in the environment. This may result in the absence of plasticity in the trait when selective pressures in the new environment do not favour it. This has been shown in some studies (e.g., diet-induced plasticity in feeding regimes in spadefoot toad tadpoles becoming genetically assimilated as tadpoles colonized new niches; Levis et al. 2018)."

Translocations studies suggest that differences in levels of plasticity in GPC in P. bistriata have a genetic basis (Fernández Campón 2008), and thus could be under selection. There is 
evidence from other studies in which plasticity has been adaptive in extreme novel environments (Wang and Althoff 2019). Based on COI genealogy, populations from Dry habitats in Cerrado and Chaco show higher divergence among them than among populations from Dry and Humid Chaco although the latter differ in GPC plasticity levels. Because COI is assumed to be neutral to selection, we expect the gene genealogy to show divergence based on the time populations have been isolated due to distance and not due to differences in selective forces. Divergence times between populations of dry and humid environments do not seem to be long enough to show in neutral markers such as COI. Finding genes associated to fitness traits will allow us to thoroughly test the adaptive value of plasticity in GPC under different environmental conditions (Tong et al. 2020). So far, the indirect data available seem to go along those lines. P. bistriata show plasticity in other foraging related traits that seem to confer higher fitness to individuals expressing it. Populations studied at the Cerrado, present plasticity in web architecture depending on different type of prey (Sandoval 1994). Thus, it will be interesting to carry out studies to examine whether differences in plasticity also occur in traits related to other aspects of its biology (e.g., physiology).

Our study provides insights into the mechanisms underlying adaptation and diversification in new environments. Phenotypic plasticity in the ancestral populations may have played a role in colonization of new habitats, triggering phenotypic changes that allow the colonizers to deal with the novel conditions (Levis and Pfennig 2016; Stein and Bell 2019). Results from this study show that plasticity in GPC was present in older populations before colonization of humid habitats. This indirect evidence suggests that GPC may have allowed $P$. bistriata to establish in habitat with different environmental conditions, however, more direct evidence is needed to support this hypothesis.

Supplementary Information The online version contains supplementary material available at https://doi. org/10.1007/s10682-021-10105-0.

Acknowledgements We would like to specially thank Luiz F. Bartoleti, for his help during field collection in Brazil. Thanks to Martín Ramírez and Marcelo Oliveira for providing specimens from Parque Nacional Copo and Estrela do Sul, respectively. We also thank the editor and two anonymous reviewers for their useful comments on an earlier draft of the manuscript. This study was funded by The National Scientific and Technical Research Council (CONICET, Argentina) through grant PIP 11220080101869 "La región austral del Chaco, su evolución histórica a través de reconstrucciones de los patrones biogeográficos y evolutivos de los componentes de su artropofauna" and the Bilateral Cooperation Programme CONICET-FAPESP to V.N. Solferini and F. Fernández Campón. This research was also supported by The National Agency for the Promotion of Science and Technology (ANPCyT, Argentina) through Grant PICT2011-2573.

\section{Compliance with ethical standards}

Conflict of interest The authors declare no conflicts of interest.

\section{References}

Addo-Bediako A, Chown S, Gaston K (2000) Thermal tolerance, climatic variability and latitude. Proc Biol Sci 267:739-745

Avilés L (1997) Causes and consequences of cooperation and permanent-sociality in spiders. In: Crespi BJ, Choe JC (eds) The evolution of social behaviour in insects and arachnids. Cambridge University Press, Cambridge, pp 476-498

Avilés L (2000) Nomadic behaviour and colony fission in a cooperative spider: life history evolution at the level of the colony? Biol J Lin Soc 70:325-339

Avilés L, Guevara J (2017) Sociality in spiders. In: Comparative social evolution, pp 188-223 
Bandelt HJ, Forster P, Röhl A (1999) Median-joining networks for inferring intraspecific phylogenies. Mol Biol Evol 16:37-48

Bartoleti LFDM, Peres EA, Sobral-Souza T, Fontes FVHM, Silva MJD, Solferini VN (2017) Phylogeography of the dry vegetation endemic species Nephila sexpunctata (Araneae: Araneidae) suggests recent expansion of the Neotropical Dry Diagonal. J Biogeogr 44:2007-2020

Beever EA, Hall LE, Varner J, Loosen AE, Dunham JB, Gahl MK, Smith FA, Lawler JJ (2017) Behavioral flexibility as a mechanism for coping with climate change. Front Ecol Environ 15:299-308

Bidegaray-Batista L, Arnedo MA (2011) Gone with the plate: the opening of the Western Mediterranean basin drove the diversification of ground-dweller spiders. BMC Evol Biol 11:317

Bilde T, Lubin Y (2011) Group living in spiders: cooperative breeding and coloniality. In: Spider behaviour: flexibility and versatility, pp 275-306

Brandt EE, Roberts KT, Williams CM, Elias DO (2020) Low temperatures impact species distributions of jumping spiders across a desert elevational cline. J Insect Physiol 122:104037

Corander J, Sirén J, Arjas E (2008) Bayesian spatial modeling of genetic population structure. Comput Stat 23:111-129

Cornwallis CK, Botero CA, Rubenstein DR, Downing PA, West SA, Griffin AS (2017) Cooperation facilitates the colonization of harsh environments. Nat Ecol Evol 1:0057

Darriba D, Taboada GL, Doallo R, Posada D (2012) JModelTest 2: more models, new heuristics and parallel computing. Nat Methods 9:772

Duckworth RA, Badyaev AV (2007) Coupling of dispersal and aggression facilitates the rapid range expansion of a passerine bird. Proc Natl Acad Sci USA 104:15017-15022

Edwards S, Beerli P (2000) Perspective: Gene divergence, population divergence, and the variance in coalescence time in phylogeographic studies. Evolution 54:1839-1854

Excoffier L, Lischer HEL (2010) Arlequin suite ver 3.5: a new series of programs to perform population genetics analyses under Linux and Windows. Mol Ecol Resour 10:564-567

Fernández Campón F (2005) Variation in life history and behavioral traits in the colonial spider Parawixia bistriata (Araneidae): some adapting responses to different environments. Dissertation, University of Tennessee

Fernández Campón F (2007) Group foraging in the colonial spider Parawixia bistriata (Araneidae): effect of resource levels and prey size. Anim Behav 74:1551-1562

Fernández Campón F (2008) More sharing when there is less: insights on spider sociality from an orbweaver's perspective. Anim Behav 75:1063-1073

Fernández Campón F (2010) Cross-habitat variation in the phenology of a colonial spider: insights from a reciprocal transplant study. Naturwissenschaften 97:279-289

Fowler HG, Gobbi N (1988) Cooperative prey capture by an orb-web spider. Naturwissenschaften 75:208-209

Framenau V, Duperre N, Blackledge TA, Vink CJ (2010) Systematics of the New Australasian Orbweaving Spider Genus Backobourkia (Araneae: Araneidae: Araneinae). Arthropod Systematics and Phylogeny 68:79-111

Fu Y-X (1997) Statistical tests of neutrality of mutations against population growth, hitchhiking and background selection. Genetics 147:915-925

Grinsted L, Lubin Y (2019) Spiders: Evolution of group living and social behavior. In: Choe JC (ed) Encyclopedia of animal behavior, 2nd edn. Academic Press, Oxford, pp 632-640

Grinsted L, Deutsch EK, Jimenez-Tenorio M, Lubin Y (2019) Evolutionary drivers of group foraging: a new framework for investigating variance in food intake and reproduction. Evolution 73:2106-2121

Grinsted L, Schou MF, Settepani V, Holm C, Bird TL, Bilde T (2020) Prey to predator body size ratio in the evolution of cooperative hunting — a social spider test case. Dev Genes Evol 230:173-184

Guisan A, Thuiller W (2005) Predicting species distribution: offering more than simple habitat models. Ecol Lett 8:993-1009

Heled J, Drummond AJ (2010) Bayesian inference of species trees from multilocus data. Mol Biol Evol 27:570-580

Hernandez PA, Graham CH, Master LL, Albert DL (2006) The effect of sample size and species characteristics on performance of different species distribution modeling methods. Ecography 29:773-785

Hernandez PA, Franke I, Herzog SK, Pacheco V, Paniagua L, Quintana HL, Soto A, Swenson JJ, Tovar C, Valqui TH, Vargas J, Young BE (2008) Predicting species distributions in poorly-studied landscapes. Biodivers Conserv 17:1353-1366

Hijmans RJ, Cameron SE, Parra JL, Jones PG, Jarvis A (2005) Very high resolution interpolated climate surfaces for global land areas. Int J Climatol 25:1965-1978 
Kellermann V, Overgaard J, Hoffmann AA, Fløjgaard C, Svenning J-C, Loeschcke V (2012) Upper thermal limits of Drosophila are linked to species distributions and strongly constrained phylogenetically. Proc Natl Acad Sci 109:16228-16233

Kuntner M, Arnedo MA, Trontelj P, Lokovšek T, Agnarsson I (2013) A molecular phylogeny of nephilid spiders: evolutionary history of a model lineage. Mol Phylogenet Evol 69:961-979

Landis MJ, Bedford T (2014) Phylowood: interactive web-based animations of biogeographic and phylogeographic histories. Bioinformatics 30:123-124

Levi HW (1992) Spiders of the orb-weaver genus Parawixia in America (Araneae: Araneidae). Bull Museum Comp Zool Harvard College 153:1-46

Levis NA, Pfennig DW (2016) Evaluating 'plasticity-first' evolution in nature: key criteria and empirical approaches. Trends Ecol Evol 31:563-574

Levis NA, Isdaner AJ, Pfennig DW (2018) Morphological novelty emerges from pre-existing phenotypic plasticity. Nat Ecol Evol 2:1289-1297

Lövy M, Šklíba J, Burda H, Chitaukali WN, Šumbera R (2012) Ecological characteristics in habitats of two African mole-rat species with different social systems in an area of sympatry: implications for the mole-rat social evolution. J Zool 286:145-153

Lubin YD (1974) Adaptive advantages and the evolution of colony formation in Cyrtophora (Araneae: Araneidae). Zool J Linnean Soc 54:321-339

Majer M, Svenning J-C, Bilde T (2015) Habitat productivity predicts the global distribution of social spiders. Front Ecol Evol 3:101

Majer M, Holm C, Lubin Y, Bilde T (2018) Cooperative foraging expands dietary niche but does not offset intra-group competition for resources in social spiders. Sci Rep 8:11828

McCormack JE, Heled J, Delaney KS, Peterson AT, Knowles LL (2011) Calibrating divergence times on species trees versus gene trees: implications for speciation history of Aphelocoma jays. Evolution 65:184-202

Muscarella R, Galante PJ, Soley-Guardia M, Boria RA, Kass JM, Uriarte M, Anderson RP (2014) ENMeval: An R package for conducting spatially independent evaluations and estimating optimal model complexity for Maxent ecological niche models. Methods Ecol Evol 5:1198-1205

Otto-Bliesner BL, Marshall SJ, Overpeck JT, Miller GH, Hu A, Members CLIP (2006) Simulating arctic climate warmth and icefield retreat in the last interglaciation. Science 311:1751-1753

Pearson RG, Raxworthy CJ, Nakamura M, Peterson AT (2007) Predicting species distributions from small numbers of occurrence records: a test case using cryptic geckos in Madagascar. J Biogeogr 34:102-117

Phillips SJ, Dudík M (2008) Modeling of species distribution with Maxent: new extensions and a comprehensive evalutation. Ecograpy 31:161-175

Powers KS, Avilés L (2007) The role of prey size and abundance in the geographical distribution of spider sociality. J Anim Ecol 76:995-1003

Quero A, Zuanon LA, Vieira C, Gonzaga MO (2020) Cooperation and conflicts during prey capture in colonies of the colonial spider Parawixia bistriata (Araneae: Araneidae). Acta Ethologica 23:79-87

Quinn CB, Akins JR, Hiller TL, Sacks BN (2018) Predicting the potential distribution of the Sierra Nevada red fox in the Oregon cascades. J Fish Wildl Manag 9:351-366

Rambaut A (2012) FigTree, version 1.4. http://tree.bio.ed.ac.uk/software/figtree

Rambaut A, Suchard MA, Xie D, Drummond AJ (2014) Tracer, version 1.6. http://beast.bio.ed.ac.uk/Tracer

Rao D (2009) Experimental evidence for the amelioration of shadow competition in an orb-web spider through the 'Ricochet' effect. Ethology 115:691-697

Rengger JR (1836) Über Spinnen Paraguays. Archiv für Naturgeschichte 1:130-132

Riechert SE (1985) Why do some spiders cooperate? Agelena consociata, a case study. Fla Entomol 68: $105-116$

Rypstra AL (1989) Foraging success of solitary and aggregated spiders: insights into flock formation. Anim Behav 37:274-281

Sandoval CP (1994) Plasticity in web design in the spider Parawixia bistriata: a response to variable prey type. Funct Ecol 8:701-707

Sobral-Souza T, Lima-Ribeiro MS, Solferini VN (2015) Biogeography of neotropical rainforests: past connections between Amazon and Atlantic Forest detected by ecological niche modeling. Evol Ecol 29:643-655

Sol D, Timmermans S, Lefebvre L (2002) Behavioural flexibility and invasion success in birds. Anim Behav 63:495-502

Spinks AC, Bennett NC, Jarvis JUM (2000) A comparison of the ecology of two populations of the common mole-rat, Cryptomys hottentotus hottentotus: the effect of aridity on food, foraging and body mass. Oecologia 125:341-349 
Stein LR, Bell AM (2019) The role of variation and plasticity in parental care during the adaptive radiation of three-spine sticklebacks. Evolution 73:1037-1044

Sunnucks P, Hales DF (1996) Numerous transposed sequences of mitochondrial cytochrome oxidase I-II in aphids of the genus Sitobion (Hemiptera: Aphididae). Mol Biol Evol 13:510-524

Tajima F (1989) Statistical method for testing the neutral mutation hypothesis by DNA polymorphism. Genetics 123:585-595

Tamura K, Ne M (1993) Estimation of the number of nucleotide substitutions in the control region of mitochondrial DNA in humans and chimpanzees. Mol Biol Evol 10:512-526

Tognelli MF, Fernández M, Marquet PA (2009) Assessing the performance of the existing and proposed network of marine protected areas to conserve marine biodiversity in Chile. Biol Cons 142:3147-3153

Tong C, Najm GM, Pinter-Wollman N, Pruitt JN, Linksvayer TA, Pisani D (2020) Comparative genomics identifies putative signatures of sociality in spiders. Genome Biol Evol 12:122-133

Trujillo-Arias N, Dantas GPM, Arbeláez-Cortés E, Naoki K, Gómez MI, Santos FR, Miyaki CY, Aleixo A, Tubaro PL, Cabanne GS (2017) The niche and phylogeography of a passerine reveal the history of biological diversification between the Andean and the Atlantic forests. Mol Phylogenet Evol 112:107-121

Uetz GW (1989) The "Ricochet effect" and prey capture in colonial spiders. Oecologia 81:154-159

Wang SP, Althoff DM (2019) Phenotypic plasticity facilitates initial colonization of a novel environment. Evolution 73:303-316

Webb JK, Letnic M, Jessop TS, Dempster T (2014) Behavioural flexibility allows an invasive vertebrate to survive in a semi-arid environment. Biol Lett 10:20131014

Whitehouse MEA, Lubin Y (2005) The functions of societies and the evolution of group living: spider societies as a test case. Biol Rev Camb Philos Soc 80:347-361

Wisz MS, Hijmans RJ, Li J, Peterson AT, Graham CH, Guisan A (2008) Effects of sample size on the performance of species distribution models. Divers Distrib 14:763-773

Wright TF, Eberhard JR, Hobson EA, Avery ML, Russello MA (2010) Behavioral flexibility and species invasions: the adaptive flexibility hypothesis. Ethol Ecol Evol 22:393-404

Yip EC, Rayor LS (2014) Maternal care and subsocial behaviour in spiders. Biol Rev 89:427-449

Yip EC, Powers KS, Avilés L (2008) Cooperative capture of large prey solves scaling challenge faced by spider societies. Proc Natl Acad Sci USA 105:11818-11822

Yip EC, Levy T, Lubin Y (2017) Bad neighbors: hunger and dominance drive spacing and position in an orb-weaving spider colony. Behav Ecol Sociobiol 71:128

Publisher's Note Springer Nature remains neutral with regard to jurisdictional claims in published maps and institutional affiliations.

\section{Authors and Affiliations}

\section{F. Fernández Campón ${ }^{1,2,3} \cdot$ V. Nisaka Solferini ${ }^{4} \cdot$ R. Carrara $^{1,2} \cdot$ A. E. Marvaldi ${ }^{5,6}$. V. Confalonieri ${ }^{7,8}$}

1 Laboratorio de Entomología, Instituto Argentino de Investigaciones de las Zonas Áridas (IADIZA), Mendoza, Argentina

2 Consejo Nacional de Investigaciones Científicas y Técnicas, Mendoza, Argentina

3 Facultad de Ciencias Exactas y Naturales, Universidad Nacional de Cuyo, Mendoza, Argentina

4 Department of Genetics, Evolution, Microbiology and Immunology, Institute of Biology, University of Campinas, Campinas, São Paulo, Brazil

5 División Entomología, Facultad de Ciencias Naturales y Museo, Universidad Nacional de La Plata, La Plata, Buenos Aires, Argentina

6 Consejo Nacional de Investigaciones Científicas y Técnicas, La Plata, Buenos Aires, Argentina

7 Instituto de Ecología, Genética y Evolución (IEGEBA), Facultad de Ciencias Exactas y Naturales, Universidad de Buenos Aires, Buenos Aires, Argentina

8 Consejo Nacional de Investigaciones Científicas y Técnicas, Buenos Aires, Argentina 